\title{
Separation of Acylglycerols from Biodiesel by High Performance Liquid Chromatography and Solid-Phase Extraction
}

\author{
Andrade, D. F.;* Mazzei, J. L.; d'Avila, L. A. \\ Rev. Virtual Quim., 2011, 3 (6), 452-466. Data de publicação na Web: 5 de dezembro de 2011 \\ http://www.uff.br/rvq
}

\section{Separação dos Acilgliceróis do Biodiesel por Cromatografia Líquida de Alta Eficiência e Extração em Fase Sólida}

Resumo: Neste estudo, um método alternativo foi desenvolvido utilizando a cromatografia líquida de alta eficiência em fase reversa não aquosa (CLAE-FRNA) para determinar a conversão e caracterizar os principais componentes do biodiesel B100 sintetizado de óleos vegetais em diversas taxas de conversão. Um novo método de extração em fase sólida (EFS), utilizando cartuchos aminopropilsilano foi proposto para enriquecer e separar os acilgliceróis (mono-, di- e triacilgliceróis) de biodiesel B100. Os óleos de soja, milho, girassol, algodão e canola foram transesterificados com metanol em refluxo sob condições diferentes, produzindo 35 produtos que foram submetidos à investigação. O método da CLAE-FRNA foi capaz de separar os ésteres metílicos de ácidos graxos (EsMAG) e as diferentes classes de acilgliceróis, tornando-se uma alternativa para monitorar a conversão de diferentes óleos vegetais. Na EFS, os EsMAG eluem seletivamente com o $n$-hexano (atingindo até $100 \%$ recuperação), enquanto que uma fração enriquecida (três a seis vezes) com os acilgliceróis, elue subsequentemente com clorofórmio/metanol 2:1. A separação das frações dos EsMAG e dos acilgliceróis deverá contribuir para a caracterização química do B100 por diversas técnicas analíticas. O conjunto das técnicas de CLAE-FRNA e EFS pode ser um novo ponto de partida para o desenvolvimento de métodos alternativos de monitoramento da qualidade de biodiesel, para o isolamento dos acilgliceróis e para a produção de materiais de referência.

Palavras-chave: Acilgliceróis; Biodiesel; CLAE; EFS.

\begin{abstract}
s
In this study an alternative method was developed using a non-aqueous reversed phase high performance liquid chromatography (NARP-HPLC) to determine conversion and characterize the principal components of B100 biodiesel obtained from vegetable oils at several conversion rates. A novel solid-phase extraction (SPE) method with aminopropylsilane cartridges was proposed to enrich and separate the acylglycerols (mono-, di- and triacylglycerols) from B100 biodiesel. Soybean, corn, sunflower, cottonseed and canola oils were transesterified with methanol under reflux to different conditions, yielding 35 products which were submitted to investigation. The NARP-HPLC method was able to separate the fatty acid methyl esters (FAME) and the different classes of acylglycerols, making it an alternative for monitoring the conversion of different vegetable oils. In SPE, FAME elute selectively with $n$-hexane (reaching up to $100 \%$ recovery), whereas a fraction enriched (three- to six-fold) with the acylglycerols, elute subsequently with chloroform/methanol 2:1. The separation of the fractions of EsMAG and acylglycerols should contribute to the chemical characterization of the B100 for several analytical techniques. The combination of NARP-HPLC and SPE could be a new starting point for monitoring the quality of biodiesel, for the isolation of acylglycerols and for the production of reference materials.
\end{abstract}

Keywords: Acylglycerols; biodiesel; HPLC; solid-phase extraction

*Universidade Federal do Rio de Janeiro, Centro de Tecnologia, Escola de Química, BI. E, S/201, Ilha do Fundão, 21949-900, Rio de Janeiro, Brazil.

M debora.franca.andrade@gmail.com

DOI: $\underline{10.5935 / 1984-6835.20110050}$

Rev. Virtual Quim. |Vol 3| |No.6| |452-466| 


\title{
Separation of Acylglycerols from Biodiesel by High Performance Liquid Chromatography and Solid-Phase Extraction
}

\author{
Débora F. de Andrade, ${ }^{a}$,* José L. Mazzei, ${ }^{b}$ Luiz A. d'Avila ${ }^{a}$ \\ a Universidade Federal do Rio de Janeiro, Centro de Tecnologia, Escola de Química, BI. E, S/201, Ilha do Fundão, \\ 21949-900, Rio de Janeiro, Brasil.

\begin{abstract}
${ }^{\mathrm{b}}$ Laboratório de Cromatografia e Espectrometria de Massas, Instituto de Tecnologia em Fármacos, FarManguinhos, Fundação Oswaldo Cruz, Rua Sizenando Nabuco 100, Manguinhos, 21041-250, Rio de Janeiro, Brasil.

* debora.franca.andrade@gmail.com
\end{abstract}

Recebido em 8 de agosto de 2011. Aceito para publicação em 2 de dezembro de 2011

\section{Introduction}

\section{Experimental}

2.1. Transesterification reactions of the vegetable oils

2.2. Characterization of the vegetable oils and transesterification products by ${ }^{1} \mathrm{H}-\mathrm{NMR}$

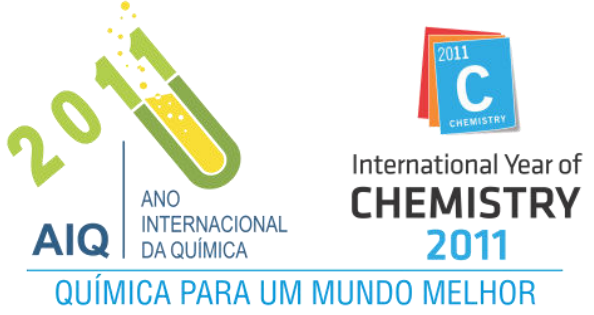

2.3. Analysis of transesterification products by HPLC

2.4. Obtaining reference materials containing FAME, MAG, DAG and TAG

2.5. Separation and isolation of acylglycerols by solid-phase extraction

\section{Results and Discussion}

3.1. Characterization of the vegetable oils and transesterification products using ${ }^{1} \mathrm{H}-\mathrm{NMR}$

3.2. Analysis of transesterification products by HPLC

3.3. Determining degree of conversion by HPLC

3.4. Obtaining reference materials containing FAME, MAG, DAG and TAG

3.5. Separation and isolation of acylglycerols by solid-phase extraction

\section{Conclusions}

\section{Introduction}

The quality of biodiesel is a priority when it is used as a fuel, because some contaminants can cause serious operational problems when employed in combustion engines. ${ }^{1}$ These include acylglycerols: triacylglycerols (TAG), which derive from the sources of production, and mono- and diacylglycerols (MAG and DAG), which derive from the incomplete conversion process. The maximum allowable quantities of these acylglycerols have been set in
American, ${ }^{2}$ European ${ }^{3}$ and Brazilian ${ }^{4}$ specifications for biodiesel. Only the Brazilian standard does not specify the alcohols and the sources of fatty chains, because of the variety of sources and process options available for producing biodiesel in Brazil, which accentuates the difficulties for its quality control.

Several chromatography techniques have been applied to analyze biodiesel and/or monitor the transesterification reaction, including: i) thin-layer chromatography; ii) gas chromatography (GC); iii) high performance liquid chromatography (HPLC); iv) gel permeation chromatography, v) size exclusion Rev. Virtual Quim. |Vol 3| |No.6| |452-466| 
chromatography, and vi) supercritical fluid chromatography. ${ }^{5-9}$ Spectroscopic techniques, such as hydrogen nuclear magnetic resonance $\left({ }^{1} \mathrm{H}-\mathrm{NMR}\right)$ and carbon nuclear magnetic resonance $\left({ }^{13} \mathrm{C}-\mathrm{NMR}\right)$, nearinfrared spectroscopy, Fourier transform spectroscopy and Raman spectroscopy have also been described in the literature for such determinations. ${ }^{8,10-12}$ Literature reviews indicate that chromatographic methods are more widely employed, especially GC. ${ }^{13,14}$ One advantage of HPLC is that extensive derivatization procedures are not normally needed.

HPLC has been described in the literature for monitoring the transesterification reaction of several vegetable oils (rapeseed, ${ }^{15}$ soybean, ${ }^{16}$ sunflower, ${ }^{7}$ corn, canola, palm and grapeseed ${ }^{6}$ ), with the purpose of monitoring the quality or the production of biodiesel. In recent years, non-aqueous reversedphase HPLC has been applied to monitor the conversion of TAG into fatty acid methyl esters (FAME) $^{15,17}$ from rapeseed, ${ }^{1,18}$ soybean, ${ }^{19,20}$ corn, cottonseed, peanut, hazelnut, walnut, sesame seed and olive oil. ${ }^{20}$ By this method, FAME, MAG, DAG, $\mathrm{TAG}^{19}$ and a few components of these classes can be separated by the difference between their equivalent carbon numbers (ECNs). The ECN is the total carbon number (TCN) of all the acyl chains in the acylglycerol minus twice the number of double bonds (NDB). This technique can be used to quantify the compounds in biodiesel or to determine the conversion obtained, making it applicable for monitoring biodiesel production and quality. Although a gel permeation chromatography technique has been described in the literature ${ }^{21}$ for determining soybean oil conversion, in this work an equation for HPLC is proposed for determining conversion from a variety of oils.

Likewise, solid-phase extraction (SPE) has also been applied in the analysis of different lipid classes, ${ }^{22-25}$ but until the present time its use in separating the constituent parts of biodiesel has not been reported. SPE permits the efficient extraction of the analytes, and also enables them to be concentrated and/or pre-purified. As such, a nonaqueous reversed-phase HPLC procedure for estimating the composition of the products from the transesterification of different oils and its use in determining conversion is proposed in this work. The results were confirmed by the characterization of the products by ${ }^{1} \mathrm{H}-\mathrm{NMR}$, a technique successfully employed to monitor the production and quality of alcoholysis reactions. ${ }^{10,11} \mathrm{~A}$ solid-phase extraction procedure was also proposed and developed for isolating acylglycerols (TAG, DAG and MAG), separating them from the FAME, which are the main biodiesel components.

\section{Experimental}

\subsection{Transesterification reactions of the vegetable oils}

The transesterification reaction was performed as described before. ${ }^{12}$ Potassium carbonate, sodium chloride and anhydrous sodium sulfate obtained from Merck (Darmstadt, Germany), and anhydrous methanol and hexane obtained from VETEC (Rio de Janeiro, Brazil) were analytical grade and employed without any further purification. Five retail brands of refined vegetable oils were transesterified without prior treatment: from soybean, corn, sunflower, canola (Liza brand, Cargill, São Paulo) and cottonseed (Salada brand, Bunge Alimentos, São Paulo). Fifty $\mathrm{mL}$ of the individual vegetable oil, previously weighed, were added to a $125 \mathrm{~mL}$ round-bottomed flask containing a magnetic stirrer and coupled to a reflux condenser. Potassium carbonate $(3 \% \mathrm{~mol})$ and methanol (oil:methanol molar ratio of 1:3 or 1:9) was added. The weight of each chemical was previously calculated based on the estimated mean molecular weight $\left(\mathrm{MW}_{\text {mean }}\right)$ of the vegetable oils, following the equation $1 .^{26}$

$$
\mathrm{MW}_{\text {mean }}=\mathrm{MW}_{\text {glycerol }}-(3 \times 17)+\frac{3 \Sigma\left(\mathrm{MW}_{\text {fat.acid }}-1\right) \times \%_{\text {fat.acid }}}{100} \quad \text { Equation } 1
$$

Equation 1. Where, $\mathrm{MW}_{\text {glycerin }}$ is the molecular weight of glycerol and $\mathrm{MW}_{\text {fat.acid }}$ is the molecular weight of each combined fatty acid present in each oil

The reaction was magnetically stirred and maintained at reflux for 5, 10, 15, 30 or $90 \mathrm{~min}$. The reaction mixture was subsequently cooled to room temperature and the excess methanol was removed in a rotary evaporator. The glycerin phase (lower) was separated and discarded in a separation funnel, 
Andrade, D. F. et al.

carrying the excess alcohol and catalyst. The upper layer, containing the target product, was extracted using $100 \mathrm{~mL}$-hexane to prevent emulsion formation. The hexane phase was extracted with distilled water $(3 \times 50 \mathrm{~mL})$ to remove any catalyst or other residues. The solvent was evaporated in a rotary evaporator yielding the FAME product, which was a clear, light yellow liquid. Traces of water were removed keeping 2 hours over anhydrous sodium sulfate. The transesterification product thus obtained was filtered through cotton, placed in an amber flask and stored in a freezer at $-10^{\circ} \mathrm{C}$ until analysis. In total, thirty-five transesterification reactions were performed without replication. Soybean, corn, sunflower and canola oils were individually employed in eight experiments: at low conversion with oil:methanol molar ratio of $1: 3$ at 5,15 and $30 \mathrm{~min}$ reflux, and others using ratio of $1: 9$ at $5,10,15,30$ and $90 \mathrm{~min}$. Cottonseed oil was transesterified only with oil:methanol molar ratio of 1:3 during $5 \mathrm{~min}$ and with ratio of $1: 9$ at 10 and $15 \mathrm{~min}$.

2.2. Characterization of the vegetable oils and transesterification products by ${ }^{1} \mathrm{H}-\mathrm{NMR}$

${ }^{1} \mathrm{H}$-NMR spectra of the vegetable oils and the respective transesterification products were obtained using a Bruker DPX-200 spectrometer (200.13 $\mathrm{MHz} /{ }^{1} \mathrm{H}$, at 4.6975 Tesla) in the conditions described before $^{12}$ aiming to characterize some structural properties such as mean molecular weight, ${ }^{13,26-30}$ unsaturated content, ${ }^{31}$ degree of unsaturation ${ }^{32,12}$ and the estimated iodine index. ${ }^{27}$ Deuterated chloroform $\left(\mathrm{CDCl}_{3}\right)$ and tetramethylsilane (TMS), both purchased from Cambridge Isotope Laboratories (USA), were used as solvent and reference material, respectively. The samples were dissolved at $12 \mathrm{mg} / \mathrm{mL}$. The following parameters were applied: spectral width $(\mathrm{SW})=20 \mathrm{ppm}$; relaxation time $=1.0 \mathrm{~s}$ (D1), 900/3 pulse of $3.0 \mu \mathrm{s}$ with $-3.0 \mathrm{~dB}$ attenuation, 16 scans at 25 ㄷ. The chemical shifts $(\delta)$ were expressed in parts per million $(\mathrm{ppm})$ of the frequency used. Electronic signals integration recovered the relative areas. The transesterification conversions of the oils were determined by two expressions proposed in the literature ${ }^{10,11}$ and recently discussed by our group. ${ }^{12}$

\subsection{Analysis of transesterification products by HPLC}

The analyses were performed in a $250 \mathrm{~mm}$ Varian Microsorb-MV column (Lake Forest, California, USA) with a $4.6 \mathrm{~mm}$ inner diameter, using an octadecylsilane phase (C18, ODS) with $5 \mu \mathrm{m}$ particle size and $100 \AA$ pore diameter attached to a guard column with ODS phase $(22 \mathrm{~mm}$ in length, $5 \mu \mathrm{m}$ particle size, $100 \AA$ pore size, Supelco, Bellefonte, USA). The mobile phase was composed of methanol (A) and $i$-propanol/n-hexane $(5: 4, \quad v / v)$ (B) (chromatography grade, Tedia, São Paulo, Brazil). The phases were previously filtered through a polytetrafluorethylene membrane (PTFE, $47 \mathrm{~mm} \times 0.5$ $\mu \mathrm{m})$ (Millipore, Bedford, USA) and sonicated for 20 min. The analyses were performed at ambient temperature with a flow rate of $1 \mathrm{~mL} / \mathrm{min}$ and UV detection at $205 \mathrm{~nm}$. The Varian (Walnut, Creck, California, USA) Polaris equipment comprised two pumps, a variable wavelength UV-Vis detector (ProStar 325) and a Rheodyne 7725i injector with 20 $\mu \mathrm{L}$ sample loop. A binary gradient with two linear ramps was established: $0 \%$ to $50 \%$ B from 0 to 15 min, followed by $50 \%$ to $100 \%$ B until 25 min run time, followed by isocratic elution at $100 \%$ B for a further $5 \mathrm{~min}$. The total run time was $30 \mathrm{~min}$. All the samples were previously filtered through a $0.45 \mu \mathrm{m}$ PTFE membrane (Millipore). The samples were injected $(10 \mu \mathrm{L})$ in triplicate at room temperature after having been diluted to $3 \%(\mathrm{p} / \mathrm{v})$ in $i$-propanol $/ n$ hexane $(5: 4, v / v)$. The chromatograms were analyzed and integrated by the Galaxie ${ }^{\mathrm{TM}}$ system data acquisition software, version 1.9.3.2 (Varian).

The relative retention time $\left(t_{R R}\right)$ for each component identified in the chromatogram was determined as the average of 20 injections, from the signals of the components selected as references for each class: monolinolein for the MAG, methyl linoleate for the FAME, oleoyl-linoleoyl-glycerol for the DAG, and trilinolein for the TAG.

The corrected area $\left(A_{c}\right)$ of each component identified was determined through the ratio of the areas obtained directly, and from the (NDB) in the components involved in the signal. The corrected areas of each class of components (FAME, MAG, DAG and TAG) were obtained through the sum of the $A_{C}$, and have direct relation with the molar composition of components.

Molar conversion by HPLC ( $\mathrm{C}_{\text {HPLC }}$ ) was determined by equation 2 , proposed in the present study. 


$$
\mathrm{C}_{\mathrm{HPLC}}=100 \% \times\left(\frac{A c_{\mathrm{FAME}}}{\mathrm{Ac}_{\mathrm{FAME}}+\mathrm{Ac}_{\mathrm{MAG}}+\left(2 \mathrm{Ac} \mathrm{c}_{\mathrm{DAG}}\right)+\left(3 \mathrm{Ac} \mathrm{c}_{\mathrm{TAG}}\right)}\right)
$$

\subsection{Obtaining reference materials containing FAME, MAG, DAG and TAG}

To develop the solid-phase extraction (SFE) technique, a reference material with known proportions of FAME, MAG, DAG and TAG was planned using a sequence of procedures: (i) finding out the composition of the initial transesterification products, established by the HPLC analysis; (ii) adjusting the composition of the different products to make the intended materials, using the least squares method; and (iii) simulating chromatograms of the planned materials using the mathematical model of statistical moments representing their chromatographic separation $^{33}$ to check the intended composition.

2.5. Separation and isolation of acylglycerols by solid-phase extraction

MAG, DAG and TAG were separated through modification of a method previously described for SPE separation of lipid classes $^{34}$. $n$-Hexane, methanol (Tedia, chromatography grade) and chloroform (Vetec, analytical grade) were employed. Preconditioned (with $2 \times 2 \mathrm{~mL}$-hexane) cartridges of aminopropyl-functionalized silica gel $(500 \mathrm{mg}, 3 \mathrm{~mL}$, Bond Elut) were loaded with $n$-hexane solution (200 or $400 \mu \mathrm{L}$ ) of the reference material at 2, 3 or $5 \%$ (v/v). Two fractions, namely 1 and 2, were eluted with $\mathrm{n}$-hexane $(8,10$ or $12 \mathrm{~mL})$ and chloroform:methanol
$(2: 1, v / v, 4 \mathrm{~mL})$, respectively, at a controlled flow rate of about $1 \mathrm{~mL} / \mathrm{min}$. Triplicates were performed. Solvents in the fractions, and in the original of the reference material solution (same volume applied on the cartridges), were evaporated under flow of nitrogen. The resultant residues were resuspended in $100 \mu \mathrm{L}$ i-propanol:n-hexane (5:4, v/v) for HPLC analysis in triplicate. The SPE data of the components were calculated based on the chromatographic results of the original reference material. One- and two-way analysis of variance (ANOVA) was performed using Microsoft Office Excel 2007 to assess the significance of volume and concentration variations over the SPE recovery and fraction compositions.

\section{Results and Discussion}

3.1. Characterization of the vegetable oils and transesterification products using ${ }^{1} \mathrm{H}-\mathrm{NMR}$

The properties (mean molecular weight, unsaturated content, degree of unsaturation and iodine index) of the vegetable oils used in this work were estimated by ${ }^{1} \mathrm{H}-\mathrm{NMR}$ using methods described in the literature ${ }^{12,13,26-32}$ (Table 1). The transesterification products were also analyzed, and it was observed that some of their characteristics were maintained.

Table 1. Characteristics of the vegetable oils used to produce the transesterification products as estimated by $N M R{ }^{1} \mathrm{H}$

\begin{tabular}{|c|c|c|c|c|c|c|}
\hline \multirow[t]{2}{*}{ Property } & \multicolumn{6}{|c|}{ Source of oil } \\
\hline & Soybean & Linseed & Corn & Sunflower & Cottonseed & Canola \\
\hline Mean molecular weight $(\mathrm{g} / \mathrm{mol})^{10,25-29}$ & 876 & 897 & 898 & 909 & 885 & 935 \\
\hline Unsaturated content $(\%)^{a, 30}$ & 85 & 71 & 84 & 89 & 71 & 91 \\
\hline Degree of unsaturation ${ }^{a, 31,37}$ & 1.47 & 1.26 & 1.28 & 1.36 & 1.17 & 1.21 \\
\hline lodine index ${ }^{26}$ & 124 & 122 & 109 & 118 & 104 & 102 \\
\hline
\end{tabular}

at was noted that these characteristics were maintained in the corresponding transesterification products, independent of the degree of conversion. 
Like most edible vegetable oils, the oils employed in this work contain a majority of TAG from unsaturated fatty acids. The characteristics encountered in the literature about their composition are presented in Table 2. It can be seen that their main components are oleic, linoleic and linolenic fatty acids, which is typical of most cooking oils.

Table 2. Chemical composition, in fatty acids (FA) (\% mass), of some vegetable oils according to data from the literature. . $^{13,28-30,35,36}$

\begin{tabular}{cccc|ccc}
\hline $\begin{array}{c}\text { FA chain } \\
\text { (TCN:NDB) }\end{array}$ & \multicolumn{7}{c}{ Source of oil } \\
\cline { 2 - 7 } & Soybean & Linseed & Corn & Sunflower & Cottonseed & Canola \\
\hline up to 14:0 & $<0.6$ & - & $<2.3$ & $<0.9$ & $<2.1$ & $<0.3$ \\
$\mathbf{1 6 : 0}$ & $6-14$ & $4-7$ & $6-14$ & $3-10$ & $17-31$ & $1.5-6.5$ \\
$\mathbf{1 8 : 0}$ & $1.4-5.5$ & $2-4$ & $0.5-5$ & $1-10$ & $0.9-4.0$ & $0.5-3.1$ \\
$\mathbf{2 0 : 0}$ and over & $<2.1$ & - & $<2.0$ & $<3.3$ & $<1.7$ & $<7$ \\
& & & & & & $<$ \\
$\mathbf{1 6 : 1}\left(\Delta^{9}\right)$ & $<0.5$ & $<0.3$ & $<0.5$ & $<1$ & $<2$ & $<3$ \\
$\mathbf{1 8 : 1}\left(\Delta^{9}\right)^{\mathbf{b}}$ & $18-30$ & $13-40$ & $24-49$ & $13-40$ & $13-44$ & $8-70$ \\
$\mathbf{1 8 : 2}\left(\boldsymbol{\Delta}^{9,12}\right)^{\mathrm{c}}$ & $44-64$ & $17.5-40$ & $6-62$ & $48-75$ & $33-59$ & $9-30$ \\
$\mathbf{1 8 : 3}\left(\boldsymbol{\Delta}^{9,12,15}\right)^{\text {d }}$ & $4-11$ & $25-60.7$ & $<2.0$ & $<0.3$ & $<2.1$ & $5-13$ \\
$\mathbf{2 0 : 1}$ and over & $<1$ & - & $<0.5$ & $<1.5$ & $<1$ & $0.1-15^{\text {e }}$ \\
\hline
\end{tabular}

a $\mathrm{TCN}$ : total carbon number and NDB: number of double bonds; ${ }^{\mathrm{b}}$ Oleic; ${ }^{\mathrm{c}}$ Linoleic; ${ }^{\mathrm{d}}$ Linolenic; ${ }^{\mathrm{e}}$ In the literature, canola oil may be called rapeseed oil, although canola is simply a refined form of rapeseed oil, and has no TAG derived from erucic acid (20:1); $\left(\Delta^{n}\right)$ - Position of double bond.

\subsection{Analysis of transesterification products by HPLC}

Figure 1 shows the separation obtained between the acylglycerls (MAG, DAG and TAG) and FAME, in low conversion transesterification reactions, by using HPLC with UV detection at $205 \mathrm{~nm}$. The components identified in Figure 1 are defined in Table 3. The method was a simplification of the Holcapek method. ${ }^{1}$ In this study, a binary gradient was employed, unlike the ternary gradient used in the original method.
Good analytical resolution was obtained, making this an alternative method for monitoring the conversion of different vegetable oils (soybean, corn, sunflower, cottonseed and canola) into biodiesel.

In the original method ${ }^{1}$ the free fatty acids (FFAs) eluted earlier than the acylglycerols, but with the binary gradient used in this work, the FFAs were probably encountered in the region of the chromatogram where the MAG eluted. However the transesterification products characterized in this work have insignificant quantities of FFAs.

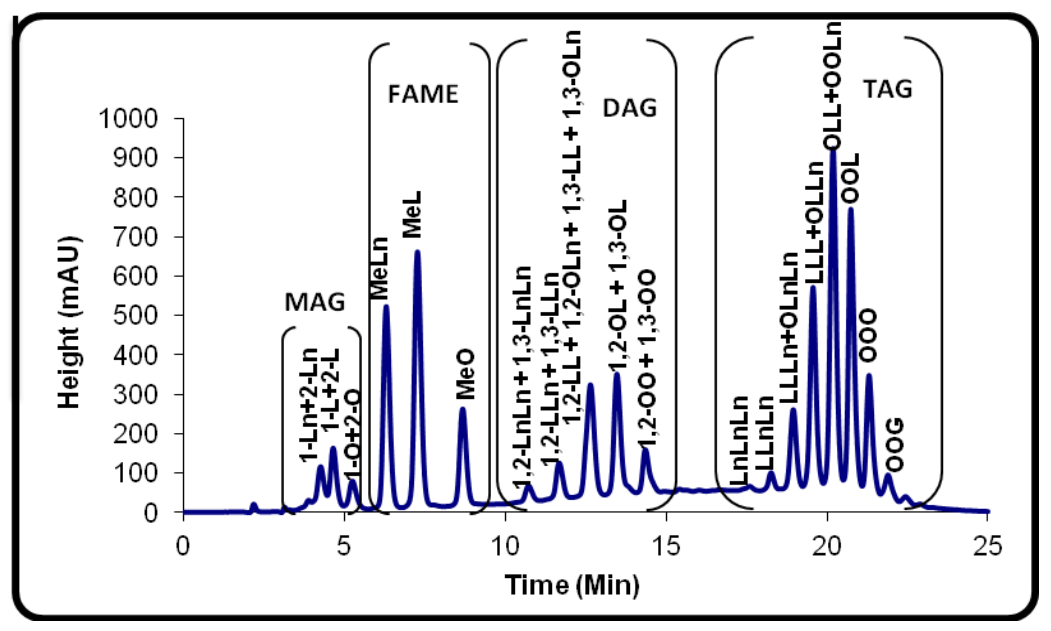

Figure 1. Chromatogram of the transesterification product from rapeseed oil with a low degree of conversion $\left(C_{G}=30 \%\right)$ after 5 min reaction, with an oil:methanol molar ratio of 1:3 
The order of elution of the acylglycerols is directly related to their equivalent carbon number (ECN) (Table 3), as is characteristic of non-aqueous reversed phase HPLC. ${ }^{1,15}$ Under the analysis conditions, the components of a given ECN were not separated. As such, the isomers in the sn-2 and sn-1 positions of the MAG (like 1- and 2-monolinolenins) and the sn-1,2 and sn-1,3 DAG isomers were not separated. Alongside the sn-1,2 and sn-1,3 DAG isomers, dilinolein was not separated from oleoyl-linolenoylglycerol, as they have the same ECN. Likewise the TAG pairs dilinoleyl-linolenoyl-glycerol/dilinolenoyl-oleoylglycerol (ECN 40), trilinolein/oleoyl-linoleoyllinolenoyl-glycerol (ECN 42) and dilinoleoyl-oleoyl- glycerol/dioleoyl-linolenoyl-glycerol (ECN 44) were not separated. In the literature there are nonaqueous reversed phase HPLC methods that enable the components of a given $\mathrm{ECN}^{1}$ to be identified and quantified using a ternary gradient. However, if the objective is to monitor the quality of the biodiesel - in other words, to determine the MAG, DAG or TAG it contains - there is no need to separate the compounds from a given ECN. As such, the method developed in this work is satisfactory for separating the major components into MAG, DAG, TAG and FAME. It gives a good resolution between the different classes and different FAME, as can be seen in Figure 1 and Table 3.

Table 3. Components identified by non-aqueous reversed phase HPLC in the transesterification products and corresponding oils

\begin{tabular}{|c|c|c|c|c|c|}
\hline Group & Name & Notation & $t_{R}{ }^{a}(\min )$ & $t_{R R}{ }^{b}$ & $\mathrm{ECN}(\mathrm{TCN})^{\mathrm{c}}$ \\
\hline \multirow[t]{3}{*}{ MAG } & Monolinolenin & $\operatorname{Ln}$ & $4.04 \pm 0.17$ & $0.920 \pm 0.025$ & $12(18)$ \\
\hline & Monolinolein * & $\mathrm{L}$ & $4.45 \pm 0.15$ & $1.000 \pm 0.000$ & $14(18)$ \\
\hline & Monoolein & 0 & $5.00 \pm 0.18$ & $1.122 \pm 0.006$ & $16(18)$ \\
\hline \multirow[t]{3}{*}{ FAME } & Linolenic acid methyl ester & MeLn & $5.71 \pm 0.22$ & $0.886 \pm 0.003$ & - \\
\hline & Linoleic acid methyl ester * & MeL & $6.44 \pm 0.26$ & $1.000 \pm 0.000$ & - \\
\hline & Oleic acid methyl ester & $\mathrm{MeO}$ & $7.43 \pm 0.33$ & $1.156 \pm 0.005$ & - \\
\hline \multirow[t]{6}{*}{ DAG } & Dilinolenin & $\operatorname{LnLn}$ & $7.94 \pm 0.37$ & $0.777 \pm 0.009$ & $24(36)$ \\
\hline & Linoleoyl-linolenoyl-glycerol & LLn & $8.58 \pm 0.40$ & $0.837 \pm 0.005$ & $26(36)$ \\
\hline & Dilinolein & LL & $9.42 \pm 0.45$ & $0.912 \pm 0.004$ & $28(36)$ \\
\hline & Oleoyl-linolenoyl-glycerol * & OLn & & & \\
\hline & Oleoyl-linoleoyl-glycerol & $\mathrm{OL}$ & $10.30 \pm 0.43$ & $1.000 \pm 0.000$ & $30(36)$ \\
\hline & Dioleyn & OO & $11.28 \pm 0.41$ & $1.093 \pm 0.005$ & $32(36)$ \\
\hline \multirow[t]{11}{*}{ TAG } & Trilinolenin & LnLnLn & $16.63 \pm 0.29$ & $0.885 \pm 0.003$ & $36(54)$ \\
\hline & Dilinolenoyl-linoleoyl-glycerol & LLnLn & $17.35 \pm 0.28$ & $0.924 \pm 0.001$ & $38(54)$ \\
\hline & Dilinoleoyl-linolenoyl-glycerol & LLLn & $18.06 \pm 0.27$ & $0.961 \pm 0.001$ & $40(54)$ \\
\hline & Dilinolenoyl-oleoyl-glycerol & OlnLn & & & \\
\hline & Trilinolein * & LLL & $18.77 \pm 0.26$ & $1.000 \pm 0.000$ & $42(54)$ \\
\hline & Oleoyl-linoleoyl-linolenoyl-glycerol & OLLn & & & \\
\hline & Dilinoleoyl-oleoyl-glycerol & OLL & $19.47 \pm 0.25$ & $1.037 \pm 0.001$ & $44(54)$ \\
\hline & Dioleoyl-linolenoyl-glycerol & OOLn & & & \\
\hline & Dioleoyl-linoleoyl-glycerol & $\mathrm{OOL}$ & $20.06 \pm 0.15$ & $1.075 \pm 0.002$ & $46(54)$ \\
\hline & Triolein & $\mathrm{OOO}$ & $20.77 \pm 0.14$ & $1.110 \pm 0.005$ & $48(54)$ \\
\hline & Dioleoyl-gadoleoyl-glycerol & OOG & $21.37 \pm 0.14$ & $1.142 \pm 0.008$ & $50(54)$ \\
\hline
\end{tabular}

${ }^{a} t_{R}$ : retention time; ${ }^{b} t_{R R}$ : relative retention time; ${ }^{c} E C N$ : equivalent carbon number; $T C N$ : total carbon number.

* Components of the signals used as reference retention times for each class.

Relative retention time $\left(t_{R R}\right)$ is defined as the retention time for the main (or reference) peak. The $t_{R R}$ for each component identified in the chromatogram was determined as the mean of 20 determinations by HPLC according to equation 3.

$$
t_{R R}=t_{R} / t_{P} \quad \text { (Equation 3) }
$$

Where: $t_{R}$ is the retention time (in minutes) of each component and $t_{p}$ is the reference peak (in minutes) for each group (1-L/2-L for MAG; MeL for FAME; $1,2-\mathrm{OL} / 1,3-\mathrm{OL} / 1,2-00 / 1,3-\mathrm{OO}$ for DAG and LLL/OLLn for TAG).

In the characterization by HPLC (Table 3 ), it was only possible to identify the components using the proposed equation for $t_{R R}$. The uncertainty when identifying the components was far lower when they were characterized by their $t_{R R}$, since their relative 
standard deviations were no greater than $1 \%$, and far lower than those of $t_{R}$ (up to $5 \%$ ). This makes it more appropriate to quantify all the components in the different classes of compounds from the biodiesel

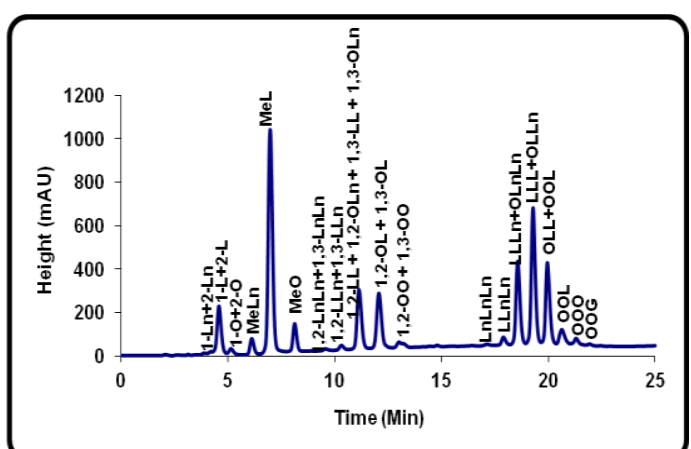

(a)

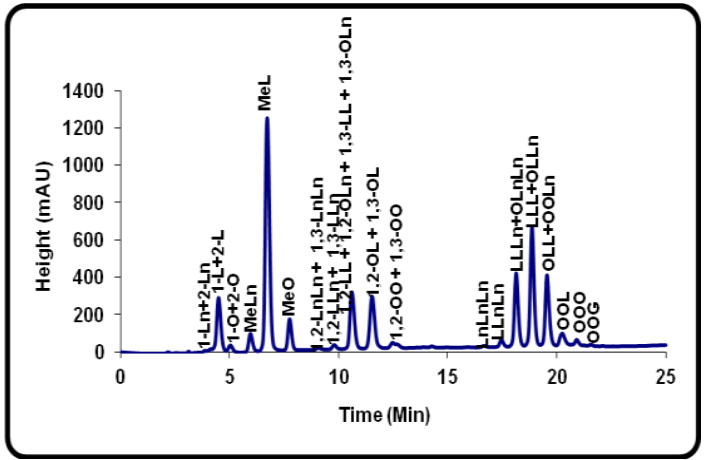

(c)

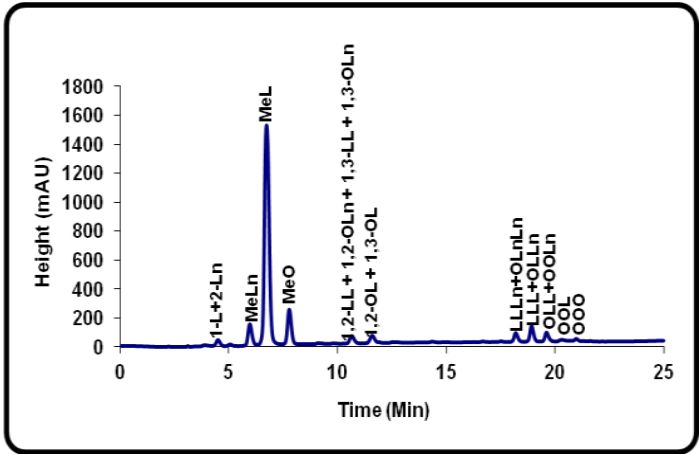

(e)

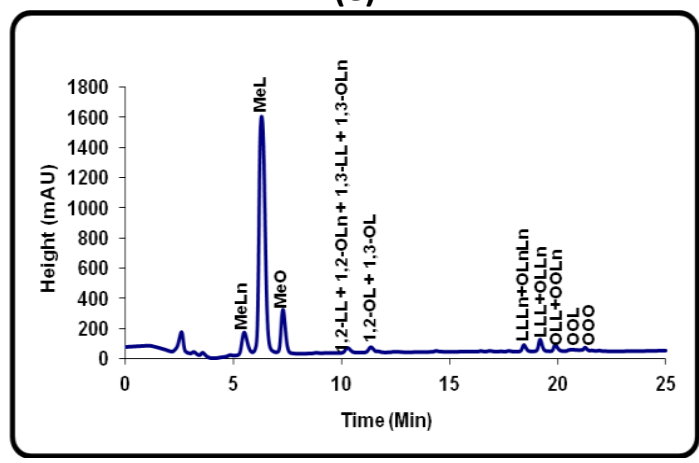

(g)
(MAG, FAME, DAG and TAG) using this method.

Figure 2 presents the chromatograms of the products of the transesterification reactions using corn oil with different degrees of conversion.

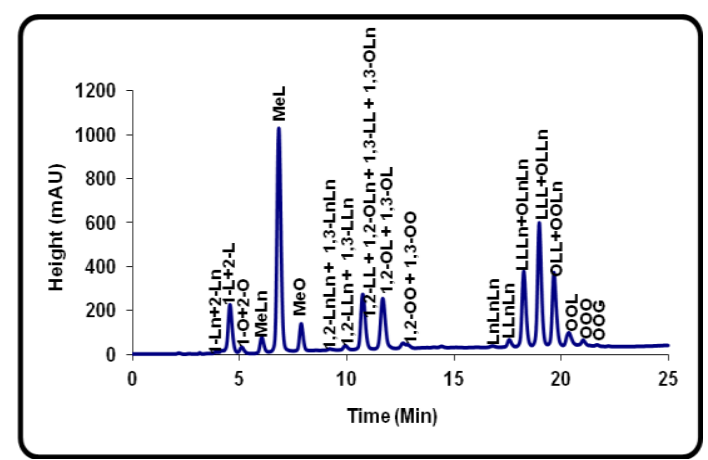

(b)

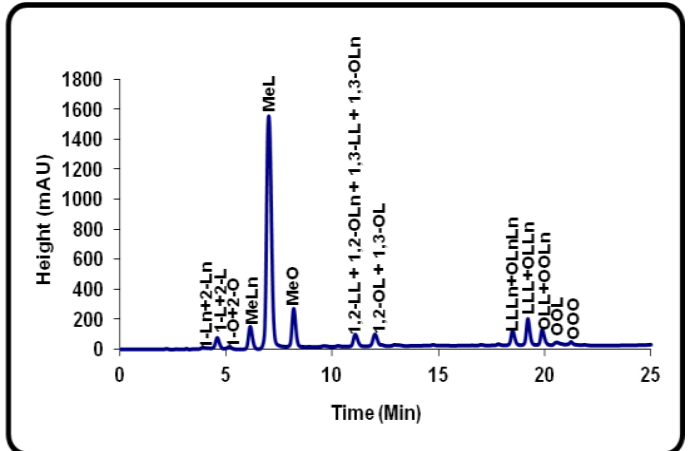

(d)

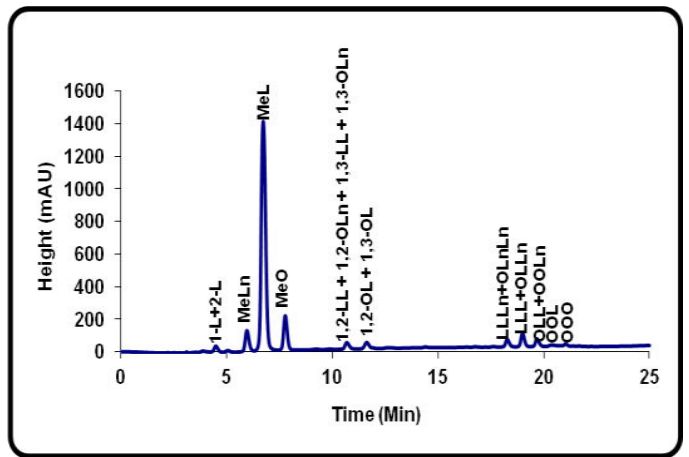

(f)

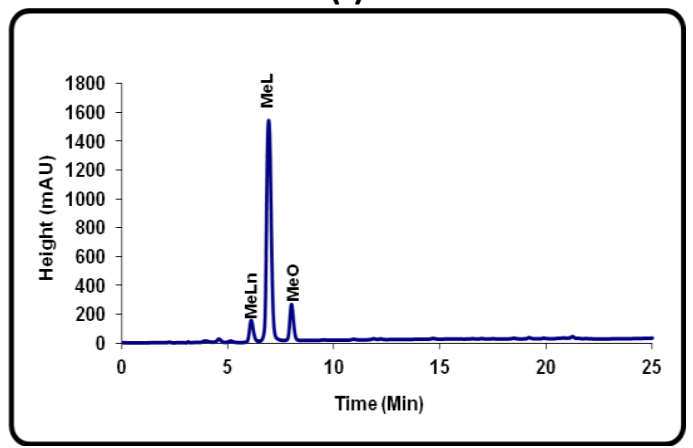

(h)

Figure 2. Chromatograms of the transesterification products from corn oil, with 5 (a), 15 (b) and 30 (c) min reaction time and an oil:methanol molar ratio of 1:3, and with 5 (d), 10 (e), 15 (f), $30(\mathrm{~g})$ and $90(\mathrm{~h})$ min reaction time and an oil:methanol molar ratio of 1:9 
We can see that the transesterification products yielded from the partial conversion of corn oil (Figures 2a-g) contained unconverted acylglycerols (TAG) and reaction intermediates (MAG and DAG) in their composition. Meanwhile, the transesterification products from total conversion (Figure $2 \mathrm{~h}$ ) were mostly made up of FAME. This demonstrates that the chromatographic profile of the transesterification products is correlated to the conversion values determined by ${ }^{1} \mathrm{H}-\mathrm{NMR}$, using the Gelbard et al expression. ${ }^{10}$ In other words, as conversion increases, the proportion of MAG, DAG and TAG diminishes, while the proportion of FAME increases. In view of all the information presented, HPLC would appear to be a useful tool for predicting the potential adulteration of biodiesel by the clandestine addition of vegetable oil, since it easily differentiates between FAME (biodiesel) and TAG (main components of vegetable oils).

The chromatographic profiles of the soybean oil and its transesterification products showed the highest intensity signals for LLLn+OLnLn and LLL+OLLn. The chromatographic profiles of the corn oil and its products presented the same relative intensity of components from the same class as the sunflower and cottonseed oils and their respective transesterification products, with the signals with the highest intensity for these oils being for LLL+OLLn.

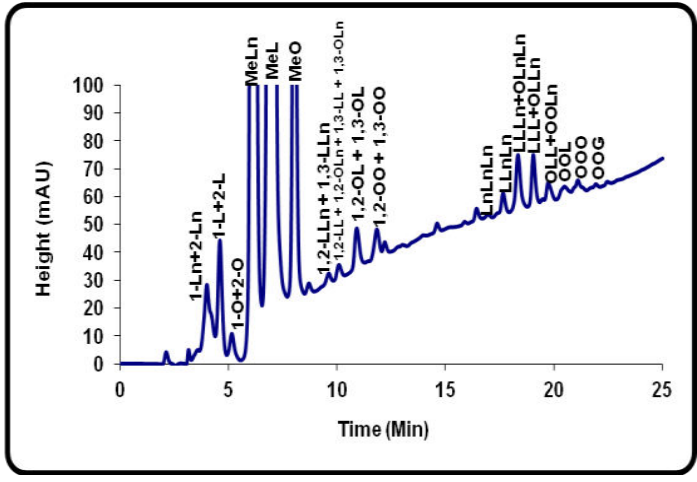

(a)
Meanwhile, the transesterification products of the canola oil showed chromatographic profiles that were quite different from the others. These results indicate there is a direct correlation with the iodine indexes of the source oils (Table 1) and show that the nonaqueous reversed phase HPLC method can be employed to estimate the oxidative stability of the transesterification products. Furthermore, the fact that different components of a given class demonstrate the same relative intensity shows that conversion does not depend on the nature of the fatty acid. This means that the relative molar composition of the FAME, MAG, DAG and TAG and their conversion into transesterification products can be determined just by monitoring the derivatives of the key fatty acids in the oils, i.e. the derivatives of oleic, linoleic and linolenic acid.

The chromatograms of the transesterification products from high degrees of conversion (> $92 \%$ ) show distinct peaks (Figure 3), demonstrating that the HPLC method was able to detect and identify small quantities of these contaminants. Traces of these components are encountered in the chromatogram of the product from $92 \%$ conversion, containing in its molar composition 3.5\% MAG, $0.8 \%$ DAG and $0.5 \%$ TAG. However, it was not possible to identify DAG or TAG in the chromatogram of the product resulting from $95 \%$ conversion.

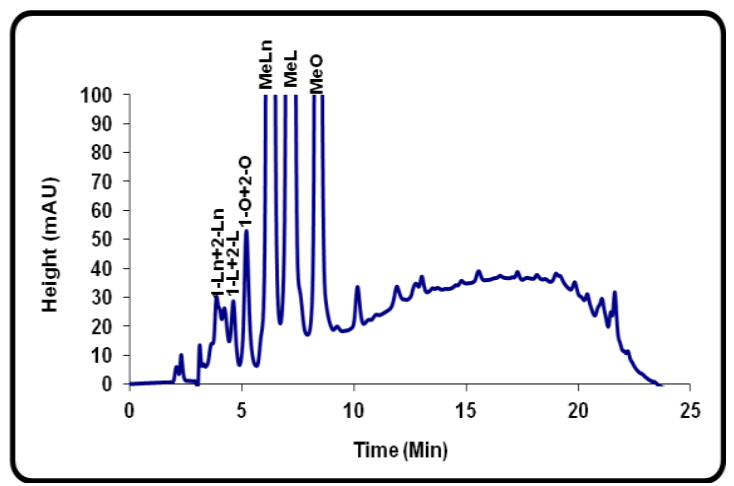

(b)

Figure 3. Amplified chromatograms of the products of transesterification reactions with high degrees of conversion using soybean oil ( $\left.a, C_{G}=92 \%\right)$ and canola oil ( $\left.b, C_{G}=95 \%\right)$ after 90 min with an oil:methanol molar ratio of $1: 9$

It is important to be able to quantify these classes of acylglycerols because higher concentrations than those established in the legislation will render the biodiesel off-spec ${ }^{2-4}$. In Figure 3 we can see that FAME (biodiesel) make up the majority of the composition, demonstrating the potential of this method for monitoring quality in biodiesel production processes.

\subsection{Determining degree of conversion by HPLC}

The conversion results obtained by HPLC using the equation proposed in this study were compared with the results obtained by ${ }^{1} \mathrm{H}-\mathrm{NMR}$, according to procedures described in the literature. ${ }^{10,11}$ NMR has been successfully applied to monitor the production 
and quality of alcoholysis reactions. ${ }^{10,11}$ We therefore analyzed the 35 transesterification products obtained from different source oils and degrees of conversion, and therefore of different compositions, from each class, using HPLC and ${ }^{1} \mathrm{H}-\mathrm{NMR}$, the results of which are presented in Table 4.

The conversion results obtained by the HPLC method proposed here and by ${ }^{1} \mathrm{H}-\mathrm{NMR}$, as described by Gelbard et al. ${ }^{10}$ and Knothe ${ }^{11}$ (Table 4), were compared using a t-test, demonstrating that the methods were statistically equivalent to one another $(P>0.05)$. This means that the expression proposed in this study for determining the degree of conversion by HPLC adequately represented the conversion of the transesterification products, whatever the source of oil or the degree of conversion.

Table 4. Results of conversion obtained by HPLC ( $\left.\mathrm{C}_{\mathrm{HPLC}}\right)$ and ${ }^{1} \mathrm{H}-\mathrm{NMR}$, according to the equations proposed by Gelbard et al. $\left(\mathrm{C}_{\mathrm{G}}\right)$ and Knothe $\left(\mathrm{C}_{\mathrm{K}}\right)$

\begin{tabular}{|c|c|c|c|c|c|}
\hline Source Oils & Oil:Methanol molar ratio & Reaction time (min) & $\mathrm{C}_{\mathrm{G}}(\%)$ & $C_{K}(\%)$ & $C_{\text {HPLC }}$ \\
\hline \multirow[t]{8}{*}{ Soybean } & $1: 3$ & 5 & 29 & 32 & $25 \pm 1$ \\
\hline & & 15 & 13 & 15 & $14 \pm 1$ \\
\hline & & 30 & 40 & 40 & $35 \pm 1$ \\
\hline & 1:9 & 5 & 81 & 81 & $78 \pm 3$ \\
\hline & & 10 & 81 & 81 & $78 \pm 2$ \\
\hline & & 15 & 83 & 85 & $83 \pm 1$ \\
\hline & & 30 & 86 & 83 & $81 \pm 1$ \\
\hline & & 90 & 92 & 90 & $97 \pm 1$ \\
\hline \multirow[t]{8}{*}{ Corn } & $1: 3$ & 5 & 38 & 40 & $40 \pm 2$ \\
\hline & & 15 & 40 & 39 & $39 \pm 1$ \\
\hline & & 30 & 46 & 44 & $41 \pm 1$ \\
\hline & $1: 9$ & 5 & 81 & 80 & $81 \pm 1$ \\
\hline & & 10 & 86 & 86 & $86 \pm 1$ \\
\hline & & 15 & 85 & 87 & $87 \pm 1$ \\
\hline & & 30 & 91 & 88 & $91 \pm 1$ \\
\hline & & 90 & 94 & 94 & $99 \pm 1$ \\
\hline \multirow[t]{8}{*}{ Sunflower } & $1: 3$ & 5 & 10 & 12 & $11 \pm 1$ \\
\hline & & 15 & 29 & 30 & $30 \pm 1$ \\
\hline & & 30 & 39 & 38 & $35 \pm 1$ \\
\hline & 1:9 & 5 & 92 & 75 & $75 \pm 1$ \\
\hline & & 10 & 80 & 73 & $75 \pm 1$ \\
\hline & & 15 & 89 & 94 & $87 \pm 1$ \\
\hline & & 30 & 91 & 89 & $89 \pm 1$ \\
\hline & & 90 & 10 & 97 & $96 \pm 1$ \\
\hline \multirow[t]{8}{*}{ Canola } & $1: 3$ & 5 & 30 & 32 & $22 \pm 2$ \\
\hline & & 15 & 48 & 47 & $35 \pm 4$ \\
\hline & & 30 & 55 & 50 & $45 \pm 2$ \\
\hline & 1:9 & 5 & 93 & 88 & $84 \pm 1$ \\
\hline & & 10 & 74 & 74 & $82 \pm 1$ \\
\hline & & 15 & 90 & 92 & $90 \pm 1$ \\
\hline & & 30 & 94 & 87 & $99 \pm 1$ \\
\hline & & 90 & 97 & 95 & $99 \pm 1$ \\
\hline \multirow[t]{3}{*}{ Cottonseed } & $1: 3$ & 5 & 9 & 12 & $9 \pm 1$ \\
\hline & $1: 9$ & 10 & 102 & 90 & $85 \pm 1$ \\
\hline & & 15 & 105 & 94 & $88 \pm 1$ \\
\hline
\end{tabular}

t-test: 1.55 between $C_{H P L C}$ and $C_{G} ; 1.20$ between $C_{H P L C}$ and $C_{k}$; and critical one-tailed t-value $=1.68$ 
3.4. Obtaining reference materials containing FAME, MAG, DAG and TAG

A reference material was planned according to the known composition of each transesterification product analyzed by HPLC and using the least squares method, in order to yield a chromatogram with high signal intensity of all the classes of interest. A simulated chromatogram of the planned reference material is shown in Figure 4a. The reference material was based on a 60:40 (v/v) mixture of two transesterification products (whose conversion had been determined, as per Table 4) from soybean and canola oil, with both being subject to 5 min reflux at an oil:methanol molar ratio of 1:3. The final reference material was analyzed by non-aqueous reversed

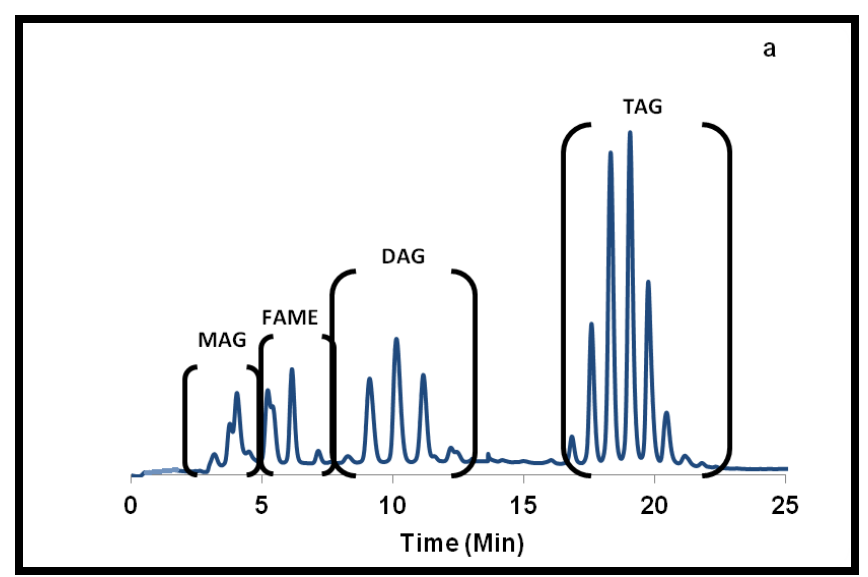

Figure 4. Simulated (a) and experimental (b) chromatograms of the reference material from the standard matrix submitted to SPE, containing $21 \pm 2 \%$ MAG, $18 \pm 3 \%$ FAME, $25 \pm 1 \%$ DAG and $36 \pm 3 \%$ TAG

\subsection{Separation and isolation of acylglycerols by solid-phase extraction}

The separation of the acylglycerols from the biodiesel by SPE was investigated using a variation on a model applied exclusively for separating classes of lipids. $^{34}$

The efficiency of the separation of the main contaminants (MAG, DAG and TAG) from the biodiesel (FAME) is illustrated in Figures $5 a$ and $5 b$, which show the HPLC chromatograms of the eluted fractions, respectively, with $n$-hexane (fraction 1 ) and

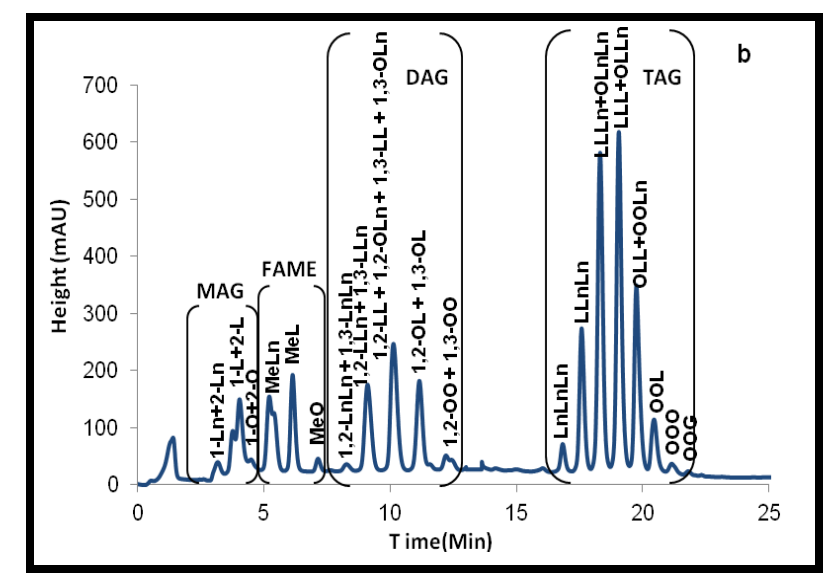

phase HPLC, resulting in the chromatogram shown in Figure 4b. Its molar composition was determined as being $21 \pm 2 \%$ MAG, $18 \pm 3 \%$ FAME, $25 \pm 1 \%$ DAG and $36 \pm 3 \%$ TAG.

If we compare the simulated (planned) chromatogram with the experimental chromatogram in Figure 4, we can see how statistical moment model can be used to represent HPLC in the preparation of the mixtures to be employed as a reference material. This application was never used for this purpose, although it has been demonstrated satisfactorily in chromatographic processes for isolating natural products, such as the isolation by HPLC of carotenoids, taxanes, ginsenosides, vitamins, steviosides ${ }^{20,33}$ and alkaloids. ${ }^{37}$ obtained from the reference material (Figure 4b).

It can be seen that before the solid-phase extraction (Figure $4 b$ ) the sample clearly showed four distinct classes of compounds (MAG, DAG, TAG and FAME). However, when this sample was submitted to SPE and eluted with $n$-hexane (Figure $5 a$ ), the predominance of FAME in fraction 1 became clear, as did the small quantities of MAG, DAG and TAG (<1\%). Meanwhile, in fraction 2 (Figure $5 b$ ), it is clear that there are significant quantities of MAG, DAG and TAG, plus a small quantity of FAME, which were not completely eluted in fraction 1. 


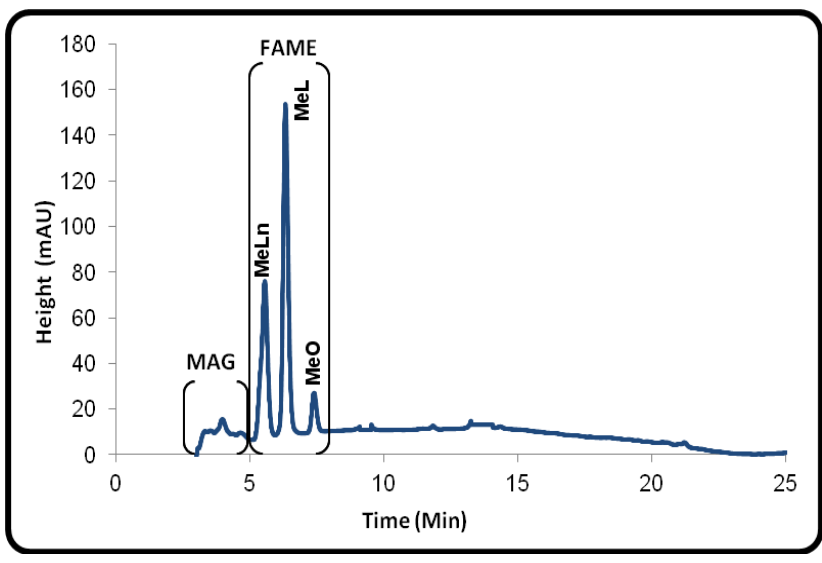

(a)

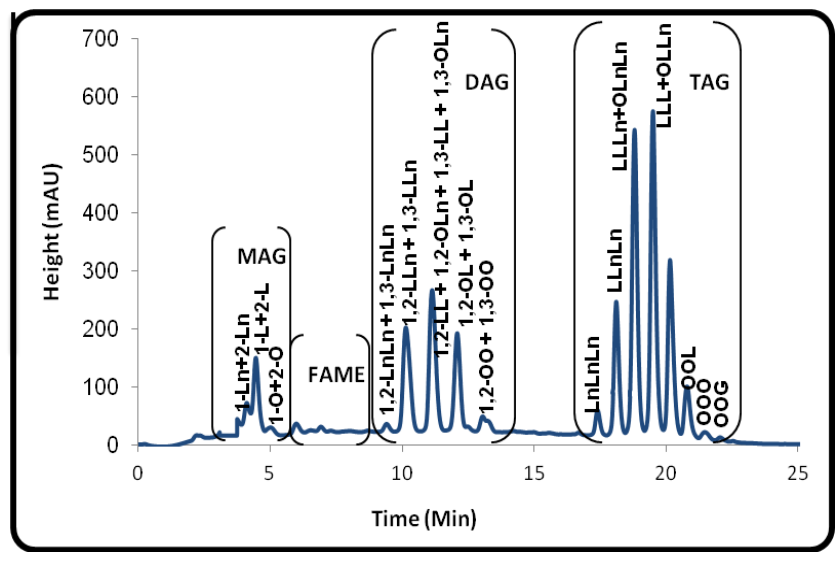

(b)

Figure 5. Chromatogram: (a) fraction 1, obtained from elution with $n$-hexane, and (b) fraction 2 , obtained from elution with chloroform:methanol (2:1)

The effect of different volumes of $n$-hexane $(8,10$ and $12 \mathrm{~mL}$ ) on the composition and recovery of both fractions was assessed (Table 5). Excellent recovery of FAME was observed for the first fraction, while excellent recovery of acylglycerols was observed in fraction 2, showing that increasing the volume of solvent in the first elution did not affect the efficiency of the separation of the acylglycerols.

Table 5. Composition and recovery of FAME and acylglycerols (MAG, DAG and TAG) from the biodiesel in the fractions eluted with different quantities of hexane, using solid-phase extraction with aminopropylsilane

\begin{tabular}{|c|c|c|c|c|c|c|c|}
\hline \multirow[t]{3}{*}{ Fraction } & \multirow[t]{3}{*}{ Class of $\mathrm{RM}^{\mathrm{a}}$} & \multicolumn{3}{|c|}{ Volume hexane $(\mathrm{mL})$} & \multicolumn{3}{|c|}{ Volume hexane $(\mathrm{mL})$} \\
\hline & & 8 & 10 & 12 & 8 & 10 & 12 \\
\hline & & \multicolumn{3}{|c|}{ Composition (\%) } & \multicolumn{3}{|c|}{ Recovery (\%) } \\
\hline $1^{b}$ & FAME & $99 \pm 1$ & $99 \pm 1$ & $99 \pm 1$ & $104 \pm 10$ & $113 \pm 15$ & $130 \pm 35$ \\
\hline \multirow[t]{3}{*}{$2^{b}$} & MAG & $18 \pm 3$ & $17 \pm 2$ & $19 \pm 3$ & $85 \pm 11$ & $86 \pm 13$ & $104 \pm 15$ \\
\hline & DAG & $33 \pm 1$ & $34 \pm 1$ & $32 \pm 1$ & $111 \pm 16$ & $125 \pm 27$ & $127 \pm 29$ \\
\hline & TAG & $48 \pm 2$ & $48 \pm 1$ & $49 \pm 3$ & $112 \pm 13$ & $124 \pm 25$ & $135 \pm 38$ \\
\hline
\end{tabular}

${ }^{\mathrm{a}} \mathrm{RM}$ : reference material constituted of $18 \pm 3 \%$ FAME; $21 \pm 2 \%$ MAG; $25 \pm 1 \%$ DAG; and $36 \pm 3 \%$ TAG. ${ }^{\text {b No }}$ acylglycerols were detected in the first fraction, and no FAME in the second.

A transesterification product (from sunflower oil after $10 \mathrm{~min}$ at an oil:methanol molar ratio of 1:9), made up of $82 \pm 2 \%$ FAME, $5 \pm 1 \%$ MAG, $6 \pm 1 \%$ DAG, and $7 \pm 1 \%$ TAG, was employed to assess the effects on the SPE process of varying the volume (200 and $400 \mu \mathrm{L})$ and the concentration (2, 3 and $5 \%$ ) of the sample, and the composition and recovery of the fractions obtained were determined (Table 6). The 8
$\mathrm{mL}$ volume of $n$-hexane was maintained for the first elution. In the first eluted fraction, the results showed good recovery of FAME, which reached $100 \%$ (from $400 \mu \mathrm{L}$ of the sample to $5 \% \mathrm{p} / \mathrm{v}$ ), and no acylglycerols in detectable quantities ( $<0.6 \%$ ). In fraction 2 , the composition of acylglycerols was enriched three- to six-fold, demonstrating the efficiency of the process. 
Table 6. Composition and recovery of FAME and acylglycerols (MAG, DAG and TAG) from the biodiesel in the fractions obtained by solid-phase extraction with aminopropylsilane

\begin{tabular}{|c|c|c|c|c|c|c|}
\hline \multirow[t]{3}{*}{ Fraction } & \multirow[t]{3}{*}{ Class of $\mathrm{RM}^{\mathrm{a}}$} & \multirow{3}{*}{$\begin{array}{c}\text { Concentration of } \\
\text { Sample } \\
(\% \mathrm{p} / \mathrm{v})\end{array}$} & \multirow{2}{*}{\multicolumn{2}{|c|}{$\begin{array}{c}\text { Molar Composition (\%) } \\
\text { Volume }(\mu \mathrm{L})\end{array}$}} & \multicolumn{2}{|c|}{ Recovery (\%) } \\
\hline & & & & & & ume $(\mu \mathrm{L})$ \\
\hline & & & 200 & 400 & 200 & 400 \\
\hline \multirow[t]{3}{*}{$1^{b}$} & FAME & 2 & $99.6 \pm 0.3$ & $99.6 \pm 0.2$ & $86.3 \pm 15.3$ & $84.7 \pm 8.5$ \\
\hline & & 3 & $99.6 \pm 0.4$ & $99.4 \pm 0.4$ & $67.0 \pm 22.1$ & $75.3 \pm 10.1$ \\
\hline & & 5 & $99.5 \pm 0.3$ & $99.4 \pm 0.2$ & $89.3 \pm 26.1$ & $100.3 \pm 12.4$ \\
\hline \multirow[t]{12}{*}{2} & MAG & 2 & $18.7 \pm 3.1$ & $16.3 \pm 5.0$ & $156.5 \pm 31.8$ & $75.7 \pm 9.1$ \\
\hline & & 3 & $18.3 \pm 6.4$ & $23.3 \pm 2.9$ & $91.0 \pm 2.8$ & $90.3 \pm 0.6$ \\
\hline & & 5 & $24.3 \pm 5.9$ & $22.0 \pm 2.0$ & $105.0 \pm 31.1$ & $108.5 \pm 9.2$ \\
\hline & FAME & 2 & $43.7 \pm 11.0$ & $33.3 \pm 15.5$ & $19.3 \pm 11.5$ & $8.3 \pm 6.1$ \\
\hline & & 3 & $41.7 \pm 16.9$ & $25.7 \pm 6.4$ & $7.00 \pm 1.0$ & $7.7 \pm 2.9$ \\
\hline & & 5 & $24.7 \pm 2.1$ & $19.7 \pm 4.9$ & $8.0 \pm 1.7$ & $8.3 \pm 4.0$ \\
\hline & DAG & 2 & $19.0 \pm 5.3$ & $19.0 \pm 2.6$ & $117.0 \pm 25.0$ & $77.7 \pm 15.3$ \\
\hline & & 3 & $19.3 \pm 5.7$ & $21.0 \pm 3.5$ & $111.7 \pm 23.5$ & $88.0 \pm 1.7$ \\
\hline & & 5 & $21.3 \pm 0.6$ & $22.0 \pm 1.0$ & $114.5 \pm 20.5$ & $122 \pm 55.0$ \\
\hline & TAG & 2 & $18.3 \pm 3.5$ & $31.0 \pm 7.5$ & $110.3 \pm 14.4$ & $83.3 \pm 4.0$ \\
\hline & & 3 & $20.7 \pm 5.1$ & $30.7 \pm 0.6$ & $93.3 \pm 34.5$ & $84.7 \pm 11.5$ \\
\hline & & 5 & $29.3 \pm 5.0$ & $36.0 \pm 3.0$ & $120.5 \pm 38.9$ & $130.5 \pm 13.4$ \\
\hline
\end{tabular}

aM: reference material constituted of $82 \pm 2 \%$ FAME, $5 \pm 1 \%$ MAG, $6 \pm 1 \%$ DAG and $7 \pm 1 \%$ TAG. ${ }^{b}$ No acylglycerols were detected in the first fraction.

The effects of the two factors studied (sample concentration and volume), both in isolation and in combination, on the dependent variables (recovery and composition of the classes of components - Table 6) were not significant $(P>0.05)$ during the SPE process. As such, the method may be established within the operating values adopted, maintaining efficient separation and enrichment of the acylglycerols: $200-400 \mu \mathrm{L}$ sample at $2-5 \% \mathrm{p} / \mathrm{v}$ in $n$ hexane, eluting FAME with 8-12 $\mathrm{mL} n$-hexane, and eluting the acylglycerol-rich fraction with chloroform:methanol, 2:1.

\section{Conclusions}

The HPLC method presented in this study, which is a simplification of the Holcapek method, ${ }^{1}$ was applied to monitor the conversion of different vegetable oils (soybean, corn, sunflower, cottonseed and canola) into fatty acid methyl esters. The degrees of conversion obtained were compared with those obtained by ${ }^{1} \mathrm{H}-\mathrm{NMR}$, according to two determination methods described in the literature. ${ }^{10,11}$ The Rev. Virtual Quim. |Vol 3| |No.6| |452-466| conversion results obtained by ${ }^{1} \mathrm{H}-\mathrm{NMR}$ and $\mathrm{HPLC}$ were not statistically different $(P>0.05)$, demonstrating that HPLC is suitable for monitoring biodiesel production processes. As such, the method developed in this study is recommended for use in monitoring biodiesel production, since it is capable of identifying the degree of conversion obtained in the transesterification reaction. Not only does this method permit the identification of fatty acid methyl esters, but it also identifies triacylglycerols (contaminants derived from the untransesterified source oil) and reaction intermediates (mono- and diacylglycerols) in a simple 25-minute run. The nonidentification of saturated compounds, by UV detection, is believed to be the only major drawback of the method developed. The main advantages of the HPLC method over the reference method (GC) is the low temperature used in the analysis, which reduces the risk of double bond isomerization, and the fact that no derivatization reagents are needed, which reduces the analysis time.

This HPLC method could also be a useful tool for predicting the potential adulteration of biodiesel by the clandestine addition of vegetable oil, since it 
easily differentiates between fatty acid methyl esters (biodiesel) and triacylglycerols. This method can also be employed to estimate the oxidative stability of vegetable oils and their transesterification products, since the areas (\%) of the major components correlate directly with the iodine indexes as estimated by ${ }^{1} \mathrm{H}$ NMR , using the method described in the literature. ${ }^{27}$

The use of chromatographic models representing HPLC to simulate chromatographic separation proved efficient for biodiesel. The novel method adopted, involving analysis and adjustment using the least squares method, could be helpful for developing a method for quantitatively analyzing biodiesel.

The method for separating the acylglycerols (MAG, DAG and TAG) from the biodiesel (FAME), using solid-phase extraction, yielded enriched fractions in the main impurity classes (MAG, DAG and TAG). This method therefore has the potential to be used in the chemical characterization of the main contaminants of biodiesel (MAG, DAG and TAG), since it concentrates them in one fraction, thereby increasing sensitivity and simplifying their characterization by analytical methods.

\section{Acknowledgements}

The authors would like to thank Agência Nacional do Petróleo, Gás Natural e Biocombustíveis for the support provided through their human resources program (PRH-13/UFRJ, Rio de Janeiro, Brazil), Conselho Nacional de Desenvolvimento Científico e Tecnológico (CNPq / Brasília, Brazil) and Fundação Carlos Chagas Filho de Amparo à Pesquisa do Estado do Rio de Janeiro (Faperj /Rio de Janeiro, Brazil) for their financial support and grants used in this work. We also thank Dr. Carlos Roland Kaiser for the analyses of ${ }^{1} \mathrm{H}-\mathrm{NMR}$ at the Nuclear Magnetic Resonance Laboratory, Instituto de Química, Universidade Federal do Rio de Janeiro.

\section{References}

${ }^{1}$ Holcapek, M.; Jandera, P.; Fischer.; Prokes, B. J. Chromatogr. A. 1999, 858, 13.[CrossRef] [PubMed]

${ }^{2}$ American Society for Testing and Materials. ASTM D6751: Standard specification for biodiesel fuel (B100) blend stock for distillate fuels. West Conshohocken, 2002.
${ }^{3}$ Deutsches Institur für Normung - DIN 14214: Automotive fuels. Fatty acid methyl esters (FAME) for diesel engines. Requirements and test methods. [German], 2003.

${ }^{4}$ Sítio da Agência Nacional de Petróleo, Gás Natural e Biocombustíveis - ANP. Resolução no 7, de 19 de março de 2008. Disponível em: <http://www.anp.org.br>. Acesso em: 10 abril 2009.

${ }^{5}$ Liu, X.; He, H.; Wang, Y.; Zhu, S.; Piao, X. Fuel 2008, 87,216. [CrossRef]

${ }^{6}$ Stavarache, C.; Vinatoru, M.; Maeda, Y.; Bandow, H. Ultrason. Sonochem. 2007, 14, 413. [CrossRef] [PubMed]

${ }^{7}$ Türkan, A.; Kalay, S. J. Chromatogr. A. 2006, 127, 34. [CrossRef] [PubMed]

${ }^{8}$ Zagonel, G. F.; Peralta-Zamora, P.; Ramos, L. P. Talanta 2004, 63, 1021. [CrossRef] [PubMed]

${ }^{9}$ Arzamendi, G.; Arguinarena, E.; Campo, I.; Gandia, L. M. Chem. Eng. J. 2006, 122, 31. [CrossRef]

${ }^{10}$ Gelbard, G.; Brès, O.; Vargas, R. M.; Vielfaure, F.; Schuchardt, U. F. J. Amer. Oil Chem.Soc. 1995, 72, 1239. [CrossRef]

${ }^{11}$ Knothe, G. J. Amer. Oil Chem. Soc. 2000, 77, 489. [CrossRef]

${ }^{12}$ Andrade, D. F.; Mazzei, J. L.; Kaiser, C. R.; d'Avila, L. A. J. Amer. Oil Chem. Soc. 2012. [CrossRef]

${ }^{13}$ Pinto, A. C.; Guarieiro, L. L. N.; Rezende, M. J. C.; Ribeiro, N. M.; Torres, E. A.; Lopes, W. A.; Pereira, P. A. P.; Andrade, J. B. J. Braz. Chem. Soc. 2005, 16, 1313. [CrossRef]

${ }^{14}$ Monteiro, M. R.; Ambrozina, A. R. P.; Lião, L. M.; Ferreira, A. G. Talanta. 2008, 77, 593. [CrossRef]

${ }^{15}$ Holcapek, M.; Jandera, P.; Fischer J. Crit. Rev. Anal. Chem. 2001, 31, 53. [CrossRef]

${ }^{16}$ Noureddini, H.; Zhu, D. J. Amer. Oil Chem. Soc. 1997, 74, 1457. [CrossRef]

${ }^{17}$ Holcapek, M.; Jandera, P.; Zderadicka, P.; Hrubá, L. J. Chromatogr. A. 2003, 1010, 195. [CrossRef]

${ }^{18}$ Kusdiana, D.; Saka, S. Fuel 2001, 80, 693. [CrossRef]

${ }^{19}$ Chen, J. W.; Wu, W. T. J. Biosci. Bioeng. 2003, 95, 466. [CrossRef] [PubMed]

${ }^{20}$ da Costa, J. L. M.; Tese de Doutorado, Universidade Federal do Rio de Janeiro, Brasil, 2004. [Link]

${ }^{21}$ Battisti, A. P.; Elias, D. T.; Dias, R.; Quadri. M. B.; Trabalho do VIII Congresso Brasileiro de Engenharia Química em Iniciação Científica, Uberlândia, 2009. Rev. Virtual Quim. |Vol 3| |No.6| |452-466| 
[Link]

${ }^{22}$ Bodennec, J.; Koul, O.; Aguado, I. Brichon, G.; Zwingelsteyn, G.; Portoukalian, J. J. Lipid Res. 2000, 41, 1524. [Link]

${ }^{23}$ Burdge, G. C.; Wright, P.; Jones, A. E.; Wootton, S. A. Br. J. Nutr. 2000, 84, 781. [PubMed] [Link]

${ }^{24}$ Russo, M. V.; De Leonardis, A.; Macciola, V. J. Food Compos. Anal. 2005, 18, 617. [CrossRef]

${ }^{25}$ Pérez-Palacios, T.; Ruiz, J.; Antequera, T. Food Chem. 2007, 102, 875. [CrossRef]

${ }^{26}$ Guarieiro, L. L. N.; Pinto, A. C.; Aguiar, P. F.; Ribeiro, N. M. Quim. Nova. 2008, 31, 421. [CrossRef]

${ }^{27}$ Redá, S. Y.; Dissertação de Mestrado, Universidade Estadual de Ponta Grossa, Brasil, 2004. [Link]

${ }^{28}$ Ma, F.; Hanna, M. A. Biores. Technol. 1999, 70, 1. [CrossRef]

${ }^{29}$ Srivastava, A.; Prasad, R. Renew Sustain. Energ. Rev. 2000, 4, 111. [CrossRef]
${ }^{30}$ Demirbas, A. Energy Conv. Managem. 2003, 44, 2093. [CrossRef]

${ }^{31}$ Ungaro, M. R. G.; Toledo, N. M. P.; Teixeira, J. P. F.; Suassuna Filho, J. Fitoquímica e Fisiologia de Plantas. 1992, 51, 1.

32 Morgenstern, M.; Cline, J., Meyer, S.; Cataldo, S. Energy Fuels 2006, 20, 1350. [CrossRef]

${ }^{33}$ Mazzei, J. L.; d’Avila, L. A. J. Liq. Chromatogr. Relat. Technol. 2003, 26, 177. [CrossRef]

${ }^{34}$ Kaluzny, M. A.; Duncan, L. A. J. Lipid Res. 1985, 26, 135. [PubMed]

${ }^{35}$ Costa Neto, P. R.; Rossi, L. F. S.; Zagonel, G. F.; Ramos, L. P. Quim. Nova. 2000, 23, 531. [CrossRef]

${ }^{36}$ Conceição, M. M.; Candeia, R. A.; Silva, F. C.; Bezzera, A. F.; Fernandes Jr, V. J.; Souza, A. G. Renew. Sustain. Energ. Rev. 2007, 11, 964. [CrossRef]

${ }^{37}$ Mazzei, J. L.; Rosario, S. L.; De Souza e Silva, R.; Siani, A. C.; Valente, L. M. M.; d'Avila, L. A. Revista de Fitoterapia 2002, 2, 289. 